\title{
Prevalence of stroke in Pakistan: Findings from Khyber Pakhtunkhwa integrated population health survey (KP-IPHS) 2016-17
}

\author{
Akhtar Sherin ${ }^{1}$, Zia Ul-Haq², Sheraz Fazid ${ }^{3}$, \\ Basharat Hussain Shah', Maria Ishaq Khattak ${ }^{5}$, Fazal Nabi ${ }^{6}$
}

\section{ABSTRACT}

Objective: To study the prevalence of stroke and associated risk factors in Khyber Pakhtunkhwa (KP) province of Pakistan.

Methods: This study was a part of cross-sectional KP Integrated Population Health Survey 2016-17 conducted on population aging $\geq 18$ years at 24 districts of KP. Primary $(n=1061)$ and secondary sampling units $(n=15724)$ were developed, based on urban/rural and socio-economic status. Each primary-unit comprised of 250-300 households. Sample was selected through a multi-staged stratified systematic cluster sampling technique by taking every $16^{\text {th }}$ household per rural and every $12^{\text {th }}$ household per urban-unit. A validated "Cincinnati Stroke Scale" for identification of stroke patients in community was used along with demographics and potential risk factors.

Results: Among the 15724 randomly selected households, 22500 participants $(51.4 \%$ females; $74.6 \%$ rural areas, mean age $42 \pm 12.6$ years) were interviewed. Stroke was identified in 271 cases (137 males, 134 females; Mean age $=43.39 \pm 0.85$ years) and prevalence of stroke was $1.2 \%$ (1200 per 100,000 population). Obesity/overweight (38.8\%), hypertension (21.8\%), smoking $(6.6 \%)$ and known diabetes mellitus $(5.9 \%)$ were the common associated risk factors of stroke. Age groups $>60$ years (adjusted $\mathrm{OR}=1.68 ; 95 \% \mathrm{Cl}$ : 1.05-2.68); urban area (adjusted $\mathrm{OR}=1.68$; 95\% Cl: 1.29-2.19); unemployment (adjusted $\mathrm{OR}=3.78 ; 95 \% \mathrm{Cl}$ : 2.49-5.73) and lower formal (primary) education (adjusted OR 2.18; $95 \% \mathrm{Cl}: 1.30-3.64$ ) were significantly associated with stroke $(\mathrm{p}<0.05)$.

Conclusion: Prevalence of stroke is $1.2 \%$ in the province of KP. Obesity, hypertension, smoking and Diabetes Mellitus are the common associated risk factors of stroke. Higher age, urban area, unemployment and lower formal education are significantly associated with stroke.

KEYWORDS: KP-IPHS, Stroke, Prevalence, Risk factors, Hypertension, Diabetes Mellitus, Obesity, Smoking, Dyslipidemias, Pakistan.

doi: https://doi.org/10.12669/pjms.36.7.2824

How to cite this:

Sherin A, Ul-Haq Z, Fazid S, Shah BH, Khattak MI, Nabi F. Prevalence of stroke in Pakistan: Findings from Khyber Pakhtunkhwa integrated population health survey (KP-IPHS) 2016-17. Pak J Med Sci. 2020;36(7):1435-1440. doi: https://doi.org/10.12669/pjms.36.7.2824

This is an Open Access article distributed under the terms of the Creative Commons Attribution License (http://creativecommons.org/licenses/by/3.0), which permits unrestricted use, distribution, and reproduction in any medium, provided the original work is properly cited.

Correspondence:

Prof. Zia Ul Haq

Khyber Medical University,

Institute of Public Health \& Social Sciences,

Peshawar, Pakistan.

Hon. Clinical Senior Lecturer with Visiting Professor, Institute of Health \& Well-Being,

University of Glasgow, UK.

E-mail: drzia80@yahoo.com

* Received for Publication:

* Revision Received:

* Revision Accepted:
May 6, 2020

September 14, 2020

September 18, 2020

\section{INTRODUCTION}

Stroke is the second leading cause of global mortality after ischemic heart disease, accounting for about $10.2 \%$ of global deaths in $2016 .{ }^{1}$ Stroke contributed for $67.3 \%$ of deaths due to all neurological disorders. ${ }^{2}$ Stroke was also responsible for $5.2 \%$ of global disability-adjusted life years (DALYs) lost in 2016. ${ }^{1}$ Worldwide, about 15 million new people develop a stroke on annual basis. ${ }^{3}$ 
Prevalence of stroke is increasing over the last three decades with annual increase of $14.3 \%$ being reported in low-incomes countries. ${ }^{4}$ Significant variations in prevalence, morbidity and mortality of stroke have been reported across different geographic 1 ocations and regions, especially in countries with different socioeconomic status..$^{4-6}$

South Asia, a major contributing region of the global stroke burden, showed gross difference in prevalence rates of stroke across different countries. ${ }^{7}$ Stroke in South Asia is different from rest of the world, in terms of higher prevalence rate, younger age, high mortality, increased burden of modifiable risk factors of stroke and some underresearched non-conventional risk factors. ${ }^{7-9}$

Pakistan, currently the sixth most populous country of the world, has limited populationbased, robust data on prevalence of stroke and its risk factors. Only two small-scale populationbased studies were conducted, a decade ago in Karachi, the single metropolitan city of Pakistan. Prevalence of stroke in these studies was $4.8 \%{ }^{10}$ $\& 19.1 \%,{ }^{11}$ highest in the region. A large scale, population-based was needed to study the prevalence of stroke in rural and urban areas of Pakistan. This study was planned to find out the prevalence of stroke and its common modifiable risk factors in adult people living in Khyber Pakhtunkhwa province of Pakistan.

\section{METHODS}

This cross-sectional study was a part of Khyber Pakhtunkhwa Integrated Population and Health Survey (KP-IPHS) 2016-17, ${ }^{12}$ to collect comprehensive information about demographic characteristics and locale-specific health-related issues of people of the KP, Pakistan. Sample size ( $n=15724$ households) was estimated by Bureau of statistics planning \& development department government of KP (http://kpbos.gov.pk/). Study was conducted during 2016-17 on adult population of either gender with age of 18 years or more, living in rural and urban areas of 24 district of KP province of Pakistan. Informed consent was taken from all participants.

A multi-staged stratified cluster sampling technique was used for the selection of sample. Sampling included all districts of Khyber Pakhtunkhwa comprising of strata from rural/ urban and low-, middle- and high-income groups. Urban areas were further divided into enumeration blocks based on the low-, middle- and highincome groups, while rural areas were divided into mohalla/villages. These were the primary sampling units (PSU's). Each PSU comprised of 250-300 households. Listing was done for selected enumeration blocks for urban and mohallas/ villages for rural areas and all households in each PSU. Secondary sampling units (SSU's) were selected for data collection through systematic random sampling by taking every $16^{\text {th }}$ household per rural PSU and every $12^{\text {th }}$ household per urban PSU. A total of 3756 households were selected from the urban areas of the seven districts and 11968 households were selected from the rural areas of these 24 districts. The total sample size of the study was 15724 households.

We used Cincinnati Stroke Scale for identification of stroke patients in community. ${ }^{13}$ This simple scale, was initially designed for out-of-hospital identification of stroke patients by physician and later on was validated for detection of patients with stroke by prehospital care providers ${ }^{14}$ as well as by even laypersons and showed an overall diagnostic accuracy of $98 \%$, sensitivity of $91 \%$ and specificity of $88 \% .{ }^{15}$

This scale was incorporated in KPIPHS questionnaire, designed to collect multidimensional information regarding various aspects of people of KP, Pakistan. We also recorded the data regarding demographic details, co-morbid conditions, body mass index (BMI), waist to hip ratio (WHR), physical activity, common modifiable risk factors of stroke including hypertension, diabetes, angina/ischemic heart disease, smoking and obesity. Data collection was done through priorly trained field workers (3040 per district) and data monitoring was done by district demographers of Population Welfare Department of KP. Data was analyzed through STATA software. Ethical approval of the study was taken from the ethical committee of the Khyber Medical University (KMU), Peshawar, Pakistan.

\section{RESULTS}

Out of 22500 participants of study, 11,556 $(51.4 \%)$ were females and $10,944(48.6 \%)$ were males. Mean age of the study participants was $42 \pm 12.6$ years. About $66.4 \%(n=14942)$ of our study population was less than 50 years of age. Majority $(74.66 \%)$ were from rural areas and about $10.9 \%$ had no formal education.

Stroke was diagnosed in 271/22500 cases and prevalence of stroke was $1.2 \%$ (1200 per 100,000 population). Male-female ratio in stroke patients 
Table-I: Characteristics of the study participants using chi-square statistics $(n=22500)$.

\begin{tabular}{|c|c|c|c|c|}
\hline Variable & & $\begin{array}{l}\text { Stroke Positive } \\
n(\%) 271(1.2)\end{array}$ & $\begin{array}{c}\text { Stroke negative } \\
n(\%) 22,229(98.8)\end{array}$ & $\begin{array}{c}\text { p-value } \\
\text { (Chi Square) }\end{array}$ \\
\hline \multirow[t]{5}{*}{ Age Group (years) } & $<30$ & 37 (13.65) & 3,599 (16.19) & $<0.001$ \\
\hline & $30-39$ & 77 (28.41) & $5,872(26.42)$ & \\
\hline & $40-49$ & $67(24.72)$ & $5,290(23.8)$ & \\
\hline & $50-59$ & $44(16.24)$ & $5,247(23.61)$ & \\
\hline & $60 \&$ above & 46 (16.97) & $2,219(9.98)$ & \\
\hline \multirow[t]{2}{*}{ Gender } & Male & $137(50.55)$ & $10,806(48.62)$ & 0.52 \\
\hline & Female & 134 (49.45) & 11,421 (51.38) & \\
\hline \multirow[t]{2}{*}{ Area } & Urban & $90(33.21)$ & $5,611(25.24)$ & 0.003 \\
\hline & Rural & $181(66.79)$ & $16,618(74.76)$ & \\
\hline \multirow[t]{3}{*}{ Employment status } & Employed & $129(47.6)$ & $11,099(49.93)$ & $<0.001$ \\
\hline & Unemployed & $74(27.31)$ & 3,546 (15.95) & \\
\hline & Housewife & $68(25.09)$ & $7,584(34.12)$ & \\
\hline \multirow[t]{4}{*}{ Years of education } & No formal education & $18(6.64)$ & 2,425 (10.91) & 0.054 \\
\hline & Primary & 168 (61.99) & $12,630(56.82)$ & \\
\hline & Secondary & $60(22.14)$ & $4,548(20.46)$ & \\
\hline & Graduate & $25(9.23)$ & $2,624(11.81)$ & \\
\hline \multirow[t]{6}{*}{ Body Mass Index } & Underweight & $33(12.18)$ & $1,471(6.62)$ & 0.001 \\
\hline & Normal weight & $133(49.08)$ & $12,026(54.1)$ & \\
\hline & Over weight & $69(25.46)$ & $4,846(21.8)$ & \\
\hline & Obese class 1 & $28(10.33)$ & 2,434 (10.95) & \\
\hline & Obese class 2 & $5(1.85)$ & $850(3.82)$ & \\
\hline & Obese class 3 & $3(1.11)$ & $602(2.71)$ & \\
\hline \multirow[t]{2}{*}{ Hypertension } & Yes & 59 (21.77) & 4,199 (18.89) & 0.229 \\
\hline & No & $212(78.23)$ & $18,028(81.11)$ & \\
\hline \multirow[t]{2}{*}{ Diabetes } & Yes & $16(5.9)$ & $843(3.79)$ & 0.07 \\
\hline & No & $255(94.1)$ & $21,386(96.21)$ & \\
\hline \multirow[t]{2}{*}{ Smoking } & Yes & $18(6.64)$ & $1,755(7.9)$ & 0.447 \\
\hline & No & $253(93.36)$ & $20,474(92.1)$ & \\
\hline
\end{tabular}

was 1.02:1. Prevalence of stroke in males \& female population was $1.3 \% \quad(\mathrm{n}=137 / 10944)$ \& $1.2 \%$ $(\mathrm{n}=134 / 11556)$ respectively. Mean age of stroke patients was $43.39 \pm 0.85$ (95\% CI: 41.71-45.07) years. About $66.8 \%(\mathrm{n}=181)$ of stroke patients were younger than 50 years of age and $16.97 \%$ $(n=46)$ were aging more than 60 years (Table-I). Prevalence of stroke in individuals less than 50 years of age was $1.2 \%$ and in those, having age more than 60 years was $2.03 \%$.

About $66.8 \% \quad(n=181 / 271)$ of stroke patients were settled in rural areas Prevalence of stroke in urban and rural areas was $1.58 \%(\mathrm{n}=90 / 5701)$ \& $1.1 \%(\mathrm{n}=181 / 16799)$ respectively. Majority $(62 \%)$ of stroke patients had some formal education at primary level.Hypertension $(21.77 \%)$, smoking (6.64\%), Diabetes Mellitus (5.9\%), Dyslipidemia $(3.32 \%)$, history of myocardial infarction (3.32\%) and angina (2.21\%) were the common risk factors of stroke. Prevalence of stroke in diabetic, hypertensive patients \& smokers was $1.9 \%, 1.4 \%$ \& $1.02 \%$ respectively.

About $25.5 \% \quad(n=69 / 271)$ of stroke patients were overweight \& 13.2\% ( $n=36)$ were obese (as per Asian cutoff score for obesity). Prevalence of stroke in overweight or obese people was $1.2 \%$ $(\mathrm{n}=105 / 8837)$. Mean BMI of stroke patients was 22.75 (95\% CI: 22.15-23.34). Data for WHR was available for only 6,695 (31.3\%) of study population including 101 subjects with stroke. Out of these 101 stroke patients, WHR was higher than normal in $87.1 \%(\mathrm{n}=88)$ of cases.

Multivariate regression analysis of various variables like age-category, gender, settlement area, employment, education status, BMI and associated risk factors in patients with stroke is 
Akhtar Sherin et al.

Table-II: Logistic regression of participants characteristic associated with having stroke $(\mathrm{n}=22500)$.

\begin{tabular}{|c|c|c|c|c|c|c|c|}
\hline \multirow[t]{2}{*}{ Variables } & & \multicolumn{3}{|c|}{ Unadjusted results } & \multicolumn{3}{|c|}{ Adjusted results } \\
\hline & & OR & $95 \% C I$ & p-value & OR & $95 \% C I$ & p-value \\
\hline \multirow[t]{5}{*}{ Age (Years) } & $<30$ & & Ref & & & $\operatorname{Ref}$ & \\
\hline & $30-39$ & 1.28 & $0.86,1.89$ & 0.226 & 1.31 & $0.88,1.95$ & 0.182 \\
\hline & $40-49$ & 1.23 & $0.82,1.84$ & 0.311 & 1.26 & $0.84,1.91$ & 0.268 \\
\hline & $50-59$ & 0.82 & $0.53,1.27$ & 0.363 & 0.66 & $0.41,1.04$ & 0.075 \\
\hline & $60 \&$ above & 2.02 & $1.30,3.12$ & 0.002 & 1.68 & $1.05,2.68$ & 0.029 \\
\hline \multirow[t]{2}{*}{ Gender } & Male & & Ref & & & $\operatorname{Ref}$ & \\
\hline & Female & 0.93 & $0.73,1.18$ & 0.526 & 1.70 & $1.18,2.45$ & 0.005 \\
\hline \multirow[t]{2}{*}{ Residence area } & Rural & & $\operatorname{Ref}$ & & & Ref & \\
\hline & Urban & 1.47 & $1.14,1.89$ & 0.003 & 1.68 & $1.29,2.19$ & $<0.001$ \\
\hline \multirow[t]{3}{*}{ employment status } & Housewife & & Ref & & & $\operatorname{Ref}$ & \\
\hline & Employed & 1.29 & $0.96,1.74$ & 0.085 & 2.26 & $1.56,3.26$ & $<0.001$ \\
\hline & Unemployed & 2.32 & $1.67,3.24$ & $<0.001$ & 3.78 & $2.49,5.73$ & 0.001 \\
\hline \multirow[t]{4}{*}{ Education status } & No formal education & & $\operatorname{Ref}$ & & & $\operatorname{Ref}$ & \\
\hline & Primary & 1.79 & $1.10,2.92$ & 0.019 & 2.18 & $1.30,3.64$ & 0.003 \\
\hline & Secondary & 1.78 & $1.05,3.02$ & 0.033 & 1.71 & $1.00,2.91$ & 0.048 \\
\hline & Graduation & 1.28 & $0.70,2.36$ & 0.421 & 1.20 & $0.65,2.23$ & 0.554 \\
\hline \multirow[t]{6}{*}{ Body mass index } & Normal weight & & $\operatorname{Ref}$ & & & $\operatorname{Ref}$ & \\
\hline & Underweight & 2.03 & $1.38,2.98$ & $<0.001$ & 1.91 & $1.29,2.83$ & 0.001 \\
\hline & Overweight & 1.29 & $0.96,1.73$ & 0.091 & 1.29 & $0.95,1.74$ & 0.099 \\
\hline & Obese class 1 & 1.04 & $0.69,1.57$ & 0.851 & 1.02 & $0.67,1.54$ & 0.933 \\
\hline & Obese class 2 & 0.53 & $0.22,1.30$ & 0.167 & 0.51 & $0.21,1.25$ & 0.141 \\
\hline & Obese class 3 & 0.45 & $0.14,1.42$ & 0.173 & 0.44 & $0.14,1.39$ & 0.161 \\
\hline \multirow[t]{2}{*}{ Hypertension } & Non-hypertensive & & Ref & & & $\operatorname{Ref}$ & \\
\hline & Hypertensive & 0.84 & $0.63,1.12$ & 0.229 & 0.88 & $0.65,1.19$ & 0.397 \\
\hline \multirow[t]{2}{*}{ Diabetes } & Non-diabetic & & Ref & & & $\operatorname{Ref}$ & \\
\hline & Diabetic & 0.63 & $0.38,1.05$ & 0.074 & 0.65 & $0.39,1.09$ & 0.104 \\
\hline \multirow[t]{2}{*}{ Smoking } & Non-smoker & & Ref & & & $\operatorname{Ref}$ & \\
\hline & Smoker & 1.20 & $0.75,1.95$ & 0.447 & 1.24 & $0.76,2.03$ & 0.385 \\
\hline
\end{tabular}

given in Table-II. Age groups $\geq 60$ years (adjusted $\mathrm{OR}=1.68$; 95\% CI: 1.05-2.68); urban area (adjusted OR $=1.68 ; \quad 95 \% \quad$ CI: 1.29-2.19); unemployment (adjusted OR=3.78; 95\% CI: 2.49-5.73) and lower formal (primary) education (adjusted OR 2.18; $95 \%$ CI: $1.30-3.64)$ were significantly associated with stroke $(\mathrm{p}<0.05)$.

\section{DISCUSSION}

In this study, prevalence of stroke in KP province of Pakistan was 1.2\% (1200 per 100,000 population). This figure is quite different from two previously conducted population based studies in Pakistan, showing 4.8\% (4800 per $100,000$ population $)^{10} \& 19.1 \%$ (19100 per 100,000 population $)^{11}$ prevalence of stroke in Pakistan. Both these studies were conducted in city of
Karachi and findings cannot be generalized to entire country. Jafar $\mathrm{TH}^{10}$ conducted study on 500 subjects of Pashtun ethnic population of Karachi and used a non-validated questionnaire for screening of stroke patients. Kamal $\mathrm{AK}^{11}$ used a validated stroke symptoms questionnaire and neurologist confirmed stroke in screened positive patients. However, the study was conducted only in a small urban slum, including 545 people of low socioeconomic status. The stroke prevalence rate $19 \%$ is the highest ever reported from the region and seems to be implausible.

Our findings are more comparable than results of Jafar $\mathrm{TH}^{10}$ \& Kamal $\mathrm{AK},{ }^{11}$ with other studies from South Asian countries. Gupta $\mathrm{R}$ et $\mathrm{al}^{16}$ reported stroke prevalence of $0.9 \%$ in India, Pakistan and Bangladesh. While Prasad $\mathrm{K}$ et $\mathrm{al}^{9}$ 
reported prevalence of stroke in 44 to 843 per $100,000(0.44 \%$ to $0.843 \%)$ in India. A systematic review and meta-analysis by Chowdhury MZI et al reported a weighted pooled prevalence $1 \%$ for stroke In Bangladesh. ${ }^{17}$ In Sri Lanka, stroke prevalence was 1040 per 100,000 (1.04\%). ${ }^{18}$ Recently, China reported stroke prevalence of 1115 per $100000 .{ }^{19}$ Variations in epidemiology of stroke has been reported across the globe as well as in South Asian countries. ${ }^{20,21}$ These variations can occur within same country and may represent the actual differences in epidemiology of stroke or showing the heterogeneity in the methodology of the studies or may denote the differences in the time trend. ${ }^{22}$

In our study, age group $\geq 60$ years was significantly associated with risk of stroke in general population. This is in accordance with previously reports that incidence of stroke is increasing with age. ${ }^{5}$ However, there is an increasing trend in incidence of stroke in younger ages. ${ }^{23}$ Stroke at a younger age is more common in South Asia than other regions. ${ }^{8}$ In our study, around two-third of stroke patients were less than fifty years of age. Stroke at a younger age is an alarming situation in Pakistan. ${ }^{24}$ Kamal et al ${ }^{11}$ reported $48.1 \%$ \& Jafar $\mathrm{TH}$ reported $30 \%$ of stroke in patient aging forty-five years or less. ${ }^{10}$ Stroke at a younger age could be due to the risk factors like Hypertension, waist-hip ratio, and cardiac risk factors, which are more significantly associated with stroke in people aging $\leq 55$ years than people aging $>55$ years. ${ }^{25}$

Rural-urban difference in the stroke prevalence is vital for South Asian countries, where almost two third of population is living in rural areas. ${ }^{7}$ This is first population-based study in Pakistan where $74.66 \%$ of study sample was proportionately selected from rural areas. The distribution of overall stroke patients in rural areas (66.8\%) was accordingly proportionate to sample selection from rural areas. However, multivariate regression analysis showed that settlement in urban area was associated with higher risk of stroke than settlement in rural areas (adjusted OR 1.68). This finding is in conformity with the results of a systematic review by Kulshreshtha A et al. who reported a higher prevalence rate of stroke in urban areas (147-471 per 100,000$)$ as compared to rural areas $(45-143$ per 100,000$)$ in South Asian countries. ${ }^{7}$
Hypertension, diabetes mellitus, dyslipidemia, smoking, obesity and ischemic heart diseases were the common risk factors of stroke in our population. These findings are in accordance with results of other studies from Pakistan and other South Asian countries. ${ }^{8,10,11,22}$ INTERSTROKE study $^{25}$ showed population attributable risks in patients of South Asian countries for Hypertension (47.2\%), Waist-to-hip ratio $32 \cdot 1 \%$, current smoking (8\%), DM (-0.1\%) and cardiac causes $(5 \cdot 2 \%)$.

Limitation of the study: This is the largest population-based study on prevalence of stroke in Pakistan and first study including both urban and rural population. However, diagnosis of stroke by healthcare workers was not counter-verified by the physicians, neurologists, or CT/MRI scan.

\section{CONCLUSION}

Prevalence of stroke in KP province of Pakistan is $1.2 \%$ (1200 per 100,000 population). Majority of patients were younger than 50 years of age. There is no significant gender-based difference in prevalence of stroke. Obesity, hypertension, smoking and Diabetes Mellitus were the common risk factors of stroke. Higher age, urban area, unemployment and lower formal education were significantly associated with stroke.

Acknowledgment: We are thankful to United Nations Population Fund (UNFPA) (for financial help for KPIPHS project) Population Welfare Department, Ministry of Population Welfare, KP Pakistan; Office of Research Innovation \& Commercialization (ORIC)- Khyber Medical University (KMU) Peshawar \& Pakistan Bureau of Statistics for technical \& logistic support.

Financial Disclosure: United Nations Population Fund (UNFPA) provided financial grant to support Khyber Pakhtunkhwa Integrated Population Health Survey (KP-IPHS) project.

\section{Conflict of Interest: None.}

\section{REFERENCES}

1. Global Health Estimates 2016: Deaths by Cause, Age, Sex, by Country and by Region, 2000-2016. Geneva, World Health Organization; 2018. [cited on April 20, 2020]. Available from URL: https://www.who.int/healthinfo/ global_burden_disease/estimates/en/

2. GBD 2015 Neurological Disorders Collaborator Group. Global, regional, and national burden of neurological disorders during 1990-2015: A systematic analysis for the Global Burden of Disease Study 2015. Lancet Neurol. 2017;16(11):877-897. doi: 10.1016/S1474-4422(17)30299-5 
3. World Health Orgnaziation. The Atlas of Heart Disease \& Stroke. Global burden of stroke. 2018. [cited on April 20, 2020] Available from URL: https://www.who.int/cardiovascular_ diseases/en/cvd_atlas_15_burden_stroke.pdf?ua=1

4. Ezejimofor MC, Chen Y-F, Kandala N-B, Ezejimofor BC, Ezeabasili AC, Stranges S, et al. Stroke survivors in low-and middle-income countries: A meta-analysis of prevalence and secular trends. J Neurol Sci. 2016;364:6876. doi: 10.1016/j.jns.2016.03.016

5. Feigin VL, Forouzanfar MH, Krishnamurthi R, Mensah GA, Connor M, Bennett DA, et al. Global and regional burden of stroke during 1990-2010: Findings from the Global Burden of Disease Study 2010. Lancet. 2014;383(9913):245254. doi: 10.1016/s0140-6736(13)61953-4

6. Krishnamurthi RV, Moran AE, Feigin VL, Barker-Collo S, Norrving B, Mensah GA, et al. Stroke prevalence, mortality and disability-adjusted life years in adults aged 20-64 years in 1990-2013: Data from the global burden of disease 2013 study. Neuroepidemiol. 2015;45(3):190-202. doi: 10.1159/000441098

7. Kulshreshtha A, Anderson LM, Goyal A, Keenan NL. Stroke in South Asia: A systematic review of epidemiologic literature from 1980 to 2010. Neuroepidemiol 2012;38(3):123-129. doi: 10.1159/000336230

8. Wasay M, Khatri IA, Kaul S. Stroke in South Asian countries. Nature Rev Neurol. 2014;10:135-143. doi 10.1038/nrneurol.2014.13

9. Prasad K, Vibha D, Meenakshi. Cerebrovascular disease in South Asia - Part I: A burning problem. JRSM Cardiovasc Dis. 2012;1(7):cvd.2012.012025. doi: 10.1258/ cvd.2012.012025

10. Jafar TH. Blood pressure, diabetes, and increased dietary salt associated with stroke-results from a communitybased study in Pakistan. J Human Hypertension. 2006;20:83-85. doi: 10.1038/sj.jhh.1001929

11. Kamal AK, Itrat A, Murtaza M, Khan M, Rasheed A, Ali A, et al. The burden of stroke and transient ischemic attack in Pakistan: A community-based prevalence study. BMC Neurol. 2009;9:58. doi: 10.1186/1471-2377-9-58

12. Ul-Haq Z, Fazid S, Sultana N, Hisam A, Shah BH, Arif $\mathrm{N}$, et al. Khyber Pakhtunkhwa Integrated Population Health Survey (KP-IPHS) 2016-17. Khyber Med Univ J. 2019;11(4):253-257. doi: 10.35845/kmuj.2019.19423

13. Kothari R, Hall K, Brott T, Broderick J. Early stroke recognition: Developing anout-of-hospital NIH Stroke Scale. Acad Emerg Med. 1997;4(10):986-990.

14. Kothari RU, Pancioli A, Liu T, Brott T, Broderick J. Cincinnati Prehospital Stroke Scale: Reproducibility and validity. Ann Emerg Med. 1999;33(4):373-378.

15. Hurwitz AS, Brice JH, Overby BA, Evenson KR. Directed Use of the Cincinnati Prehospital Stroke Scale by Laypersons. Prehospital Emerg Care. 2005;9:292-296.

16. Gupta R, Islam S, Mony P, Kutty VR, Mohan V, Kumar R, et al. Socioeconomic factors and use of secondary preventive therapies for cardiovascular diseases in South Asia: The PURE study. Eur J Prev Cardiol. 2015;22(10):1261-1271. doi: $10.1177 / 2047487314540386$

17. Chowdhury MZI, Haque MA, Farhana Z, Anik AM, Chowdhury AH, Haque SM, et al. Prevalence of cardiovascular disease among Bangladeshi adult population: A systematic review and meta-analysis of the studies. Vasc Health Risk Manag. 2018;14:165-181. doi: 10.2147/VHRM.S166111

18. Chang T, Gajasinghe S, Arambepola C. Prevalence of stroke and its risk factors in urban Sri Lanka: Populationbased study. Stroke. 2015;46:2965-2968. doi: 10.1161/ STROKEAHA.115.01
19. Wang $W$, Jiang $B$, Sun $H, R u$ X, Sun $D$, Wang $L$, et al. Prevalence, Incidence, and Mortality of Stroke in China: Results from a Nationwide Population-Based Survey of 480687 Adults. Circulation. 2017;135(8):759-771. doi: 10.1161/CIRCULATIONAHA.116.025250

20. Feigin VL, Norrving B, Mensah GA. Global burden of stroke. Circ Res. 2017;120(3):439-448. doi: 10.1161/ CIRCRESAHA.116.308413

21. Gunarathne A, Patel JV, Gammon B, Gill PS, Hughes EA, Lip GY. Ischemic stroke in South Asians: A review of the epidemiology, pathophysiology, and ethnicityrelated nical features. Stroke 2009;40(6):e415-e423. doi: 10.1161/ STROKEAHA.108.535724

22. Kaul S. Stroke in India: Are we different from the world. Pak J Neurol Sci. 2007;2:158-164.

23. Kissela BM, Khoury JC, Alwell K, Moomaw CJ, Woo $\mathrm{D}$, Adeoye $\mathrm{O}$, et al. Age at stroke: Temporal trends in stroke incidence in a large, biracial population. Neurology. 2012;79(17):1781-1787. doi: 10.1212/ WNL.0b013e318270401d

24. Hashmi M, Khan M, Wasay M. Growing burden of stroke in Pakistan: A review of progress and limitations. Int J Stroke. 2013;8(7):575-581. doi: 10.1111/j.1747-4949.2012.00827.x

25. O'Donnell MJ, Chin SL, Rangarajan S, Xavier D, Liu L, Zhang $\mathrm{H}$, et al. Global and regional effects of potentially modifiable risk factors associated with acute stroke in 32 countries (INTERSTROKE): A case-control study. Lancet. 2016;388(10046):761-775. doi: 10.1016/S01406736(16)30506-2

\section{Authors' Contribution:}

AS: Conceived idea, data collection, manuscript writing and final approval of manuscript.

ZUH: Study design, data collection, data analysis, manuscript writing, and final approval of manuscript.

SF \& BHS: Data Analysis \& interpretation of data, critical review \& and final approval of manuscript. MIK \& FN: Supervised data collection, critical review \& and final approval of manuscript.

Authors:

1. Akhtar Sherin

Khyber Medical University, Institute of Medical Sciences, DHQ Hospital Kohat, Pakistan.

2. Zia Ul-Haq,

Vice Chancellor/ Professor \& Dean, Institute of Public Health.

Visiting Professor Institute of Health \& Well-being, University of Glasgow, UK.

3. Sheraz Fazid Institute of Public Health, KMU

4. Basharat Hussain Shah

5. Maria Ishaq Khattak Lecturer, Institute of Public Health, KMU

6. Fazal Nabi

Population Welfare Department, Government of Khyber Pakhtunkhwa, Peshawar, Pakistan.

1-5: Khyber Medical University, Institute of Public Health \& Social Sciences, Peshawar, Pakistan. 